\title{
A sustentabilidade sob a perspectiva da gestão escolar: desafios e possibilidades
}

\author{
La sostenibilidad desde la perspectiva de la gestión escolar: desafíos y \\ posibilidades
}

\section{Sustainability from a school management perspective: challenges and possibilities}

\author{
Angela Patricia Rodrigues da Silva ${ }^{1}$ \\ Andréia Veridiana Antich ${ }^{2}$
}

\begin{abstract}
Resumo
Esta pesquisa qualitativa analisa a concepção da gestão escolar sobre a sustentabilidade. Além disso, buscou compreender como o desenvolvimento sustentável e a consciência ecológica podem ser construídos com o suporte da Educação Ambiental, tendo a gestão escolar como mediadora do processo. O principal instrumento para o levantamento de dados foram entrevistas semiestruturadas com três gestoras de escolas estaduais de ensino fundamental do município de São Sebastião do Caí/RS. Para a análise dos dados, utilizaram-se princípios da Análise de Conteúdo. A partir deste estudo, pode-se compreender que apesar do termo sustentabilidade ser utilizado e ações serem realizadas no ambiente escolar, ainda se encontra imprecisão sobre o conceito. Também, percebeu-se a necessidade de oferta de formação continuada para aprofundar os estudos sobre o tema, assim como possibilitar o desenvolvimento de práticas e ações sustentáveis dentro e fora do ambiente escolar.
\end{abstract}

Palavras-chave: Sustentabilidade. Educação Ambiental. Gestão Escolar

\section{Resumen}

Esta investigación cualitativa analiza la concepción de la gestión escolar en la sostenibilidad. Además, buscó comprender cómo el desarrollo sostenible y la conciencia ecológica pueden ser construidos, con el apoyo de la Educación Ambiental, teniendo a la gestión escolar como mediadora del proceso. El instrumento principal para el levantamiento de datos fue entrevistas semiestructuradas con tres gestoras de escuelas estatales de enseñanza fundamental del municipio de São Sebastião do Caí / RS. Para el análisis de los datos, se utilizaron principios del Análisis de Contenido. A partir de ese estudio se puede comprender que a pesar del término sustentabilidad ser utilizado y acciones ser realizadas en el ambiente escolar, todavía se encuentran imprecisión sobre el concepto. Además, era necesario ofrecer educación continua para profundizar los estudios sobre el tema, así como permitir el desarrollo de prácticas y acciones sostenibles dentro y fuera del entorno escolar.

Palabras clave: Sostenibilidad. Educación ambiental. Gestión Escolar.

\begin{abstract}
This qualitative research analyzes the conception of school management about sustainability. Furthermore, it seeks to understand how sustainable development and ecological awareness can be built, supported by Environmental Education, with school management as the mediator of the process. The main tool for data gathering was semistructured interviews with three public female educational managers from elementary school s in the town of São Sebastião do Caí located in the state of Rio Grande do Sul, in Brazil. Content analysis principles were used to interpret the data. This study shows that, although the word sustainability is being used and that actions are being taken in schools, the concept is not yet clear. Additionally, there is a need to offer continuing education to deepen the studies on the subject, as well as to enable the development of sustainable practices and actions inside and outside the school environment.
\end{abstract}

\footnotetext{
${ }^{1}$ Graduada em Ciências Biológica, pela Universidade da Região da Campanha, URCAMP, Bagé, Rio Grande do Sul. E-mail: prof.angelapatricia@gmail.com

${ }^{2}$ Doutoranda em Educação; Universidade do Vale do Rio dos Sinos - UNISINOS; São Leopoldo, Rio Grande do Sul, Brasil; andreia.antich@feliz.ifrs.edu.br
} 
Keywords: sustainability. Environmental Education. School management.

\title{
1. Introdução
}

No contexto atual, entende-se a necessidade das atitudes sustentáveis constituírem e integrarem os anseios da sociedade contemporânea, a qual sofre consequências severas acarretadas por um dos impactos do sistema capitalista: o incentivo de consumo desenfreado. Como resultado dessa ação, caminha-se rumo a um colapso que envolve a degradação planetária. Deste modo, torna-se imprescindível que os sujeitos sociais compreendam seu papel no ambiente em que vivem e que dele fazem parte, entendendo que suas ações refletem em reações para o todo. Ao tratar sobre os movimentos a serem instigados para construção da consciência ecológica e de atitudes sustentáveis, Gadotti (1998, p. 11) salienta:

\begin{abstract}
O movimento ecológico, como todo movimento social e político, não é um movimento neutro. Nele também, como movimento complexo e pluralista, se manifestam os interesses de grandes corporações. O que nos interessa, enquanto educadores, não é combater todas as formas de sua manifestação, mas entrar no seu campo e construir, a partir do seu interior, uma perspectiva popular e democrática de defesa da ecologia. Ele pode ser um espaço importante de luta em favor dos seres humanos mais empobrecidos pelo modelo econômico capitalista globalizado. Mas trata-se, acima de tudo, de salvar o planeta. Sem que o planeta seja preservado, as lutas por melhores relações sociais e pela justa distribuição da riqueza produzida perdem sentido, pois de nada adiantarão estas conquistas se não tivermos um planeta saudável para habitar (GADOTTI, 1998, p. 11).
\end{abstract}

Mediante a tais inquietudes, na pesquisa realizada, buscou-se compreender e aprofundar o conceito de sustentabilidade articulado às questões do processo de construção da gestão escolar democrática. Dessa forma, teve como objetivo balizador: analisar a concepção de sustentabilidade dos gestores escolares da rede estadual de ensino fundamental do município de São Sebastião do Caí/RS e como possibilitam/mediam ações de sustentabilidade nas escolas.

$\mathrm{O}$ estudo se caracterizou como uma pesquisa qualitativa, à medida que o principal instrumento para levantamento de dados foram as entrevistas semiestruturadas com três gestoras da rede estadual de ensino do munícipio selecionado no vale do Rio Caí / RS. A entrevista foi gravada e as participantes assinaram o Termo de Consentimento Livre e Esclarecido, como forma de garantia e obtenção da autorização das entrevistadas para a coleta de dados e uso posterior para a análise. Os dados foram analisados a partir de princípios da Análise de Conteúdo.

Assim sendo, nossa intenção para este artigo não é trazer respostas definitivas e nem prescrever receitas para o tema discutido, mas colaborar com o debate no campo educacional, 
com o propósito de ir ao encontro de reflexões sobre o tema da sustentabilidade articulado à área da gestão escolar, tendo em vista "a melhoria da qualidade da educação que estamos construindo no Brasil.” (RIOS, 2002, p. 155).

Para tanto, organizamos o presente estudo em três seções. Na primeira seção, tratamos dos desafios e das possibilidades apresentados à gestão escolar, ao mediar práticas voltadas à sustentabilidade. Na segunda seção, tratamos sobre o conceito da sustentabilidade, fazendo uma breve incursão histórica sobre seu desenvolvimento, o qual tem como base a área da Educação Ambiental. Já na terceira seção elencamos os dados analisados através das entrevistas, desvelando a percepção das gestoras sobre o conceito de sustentabilidade e as ações sustentáveis realizadas na escola.

\section{A mediação de práticas voltadas à sustentabilidade: desafios e possibilidades da gestão escolar}

O ambiente escolar é um espaço para os processos de ensino e de aprendizagem plausíveis de desafios e possibilidades para a mudança de pensamentos e de práticas sociais voltadas à sustentabilidade. Para Oliveira, Moraes, Dourado (2012), o conhecimento das políticas públicas, do processo pedagógico e dos recursos humanos são elementos relevantes para a construção e balizamento do trabalho da gestão escolar. Nesse aspecto, as possibilidades de efetivar ações sustentáveis são reveladas nas mais variadas formas, e os envolvidos no processo educacional precisam sentir-se à vontade para participar das decisões de implementação das práticas, bem como, para propor alternativas.

Segundo Libâneo (2004), as transformações nas esferas social, cultural e econômica demandam mudanças à escola, afirmando que, "a escola necessária para fazer frente a essas realidades é a que provê formação cultural e científica, que possibilita o contato dos alunos com a cultura, aquela cultura provida pela ciência, pela técnica, pela linguagem, pela estética, pela ética". (LIBÂNEO, 2004, p. 46). Nesse sentido, para fazer frente às exigências contemporâneas, a gestão escolar tem um papel fundamental nesse processo formativo e também para desenvolvê-lo junto à comunidade escolar. Essa composta pela equipe diretiva, docentes, discentes, pais ou responsáveis, funcionários e a comunidade local. No entanto, paralelamente, apresentam-se complexos desafios para efetivá-lo, mesmo buscando construí-lo mediante o processo de gestão democrática. Ao conceituar gestão, Libâneo (2004, p. 349) assevera:

A gestão é um conjunto de atividades e do acompanhamento do trabalho das pessoas, estes trabalhos gerenciando as atribuições dos membros da equipe por um melhor desempenho. Por gestão democrática podemos compreender que há ênfase sobre as relações humanas, e participação das decisões com ações efetivas da instituição escolar, tendo como princípio a autonomia da escola e da comunidade, e esta em conjunto, participando ativamente das decisões escolares. (LIBÂNEO, 2004, p. 349). 
Entende-se que a mobilização por mudanças nas relações humanas e essas com o comprometimento de cuidados e preservação do meio ambiente são cada vez mais pertinentes na sociedade atual, e para além disso, entra em acordo com a perspectiva autônoma e democrática da gestão escolar. Segundo Gadotti (1998), para esse processo, a compreensão do conceito em sustentabilidade far-se-á necessário, pois,

O desenvolvimento sustentável, mais do que um conceito científico, é uma ideiaforça, uma ideia mobilizadora. A escala local tem que ser compatível com uma escala planetária. Daí a importância da articulação com o poder público. As pessoas, a Sociedade Civil em parceria com o Estado, precisam dar sua parcela de contribuição para criar cidades e campos saudáveis, sustentáveis, isto é, com qualidade de vida. (GADOTTI, 1998, p.2).

A sustentabilidade sendo um tema interdisciplinar, a qual integra a Educação ambiental, pode ser vista como potencial para a gestão escolar promover ações no ambiente escolar e a conscientização dos alunos e da comunidade local. Nesse sentido, a percepção da gestão escolar sobre o conceito de sustentabilidade pode repercutir em ações inovadoras no processo de ensino e de aprendizagem, favorecendo a formação de cidadãos críticos, responsáveis e conscientes de suas atitudes em relação ao meio ambiente.

A partir da Lei de $\mathrm{n}^{\circ}$ 9.394, de 20 de dezembro de 1996, Lei das Diretrizes e Bases da Educação Brasileira, institui-se a gestão escolar sob a perspectiva democrática, na qual a autonomia e a participação são alguns dos eixos fundamentais para a construção desse processo. Libâneo (2012) salienta que

\begin{abstract}
A participação é o principal meio de assegurar a gestão democrática, possibilitando o envolvimento de todos os integrantes da escola no processo de tomada de decisões e no funcionamento da organização escolar. A participação proporciona melhor conhecimento dos objetivos e metas da escola, de sua estrutura organizacional e de sua dinâmica, de suas relações com a comunidade, e propicia de um clima de trabalho favorável a maior aproximação entre professores, alunos, pais e funcionários. (LIBÂNEO, 2012, p. 450).
\end{abstract}

Dessa forma, a partir da viabilização do processo de gestão democrática, entende-se que pode haver possibilidade do gestor instigar a sua comunidade escolar a desenvolver práticas e ações de sustentabilidade. Essa mediação integra uma das dimensões que compõe o trabalho da gestão escolar: a dimensão pedagógica. A dimensão administrativa e a financeira também constituem a prática cotidiana desse profissional, no entanto, Lück (2009, p. 95) salienta que “[...] de todas as dimensões da gestão escolar, a gestão pedagógica é a mais importante, pois está mais diretamente envolvida com o foco da escola, que é o de promover aprendizagem e formação dos alunos."

Portanto, essa dimensão está diretamente articulada ao que objetiva essa pesquisa, visto que ela fundamenta a ação do gestor ao promover ou fomentar, no ambiente escolar, o desenvolvimento sustentável a partir da contextualização da Educação Ambiental. Os gestores 
escolares e os educadores têm a possibilidade de mediarem a construção de referenciais ambientais e usá-los como instrumentos para o desenvolvimento de práticas sociais centradas no conceito da natureza, pluralizando-os para a comunidade local.

\section{A sustentabilidade e a educação ambiental}

O termo e o conceito de sustentabilidade tem base e sustentação na área da Educação Ambiental, no início da década de 1970. Entretanto, a Educação Ambiental passou por constantes mudanças em diferentes momentos históricos, tendo seu amparo na Constituição Federal de 1988, nos artigos 205 e 255 e também na Lei № 9.795/99 que institui a política Nacional de Educação Ambiental e evidencia a sua relevância em seu artigo $1^{\circ}$,

Entendem-se por educação ambiental os processos por meio dos quais o indivíduo e a coletividade constroem valores sociais, conhecimentos, habilidades, atitudes e competências voltadas para a conservação do meio ambiente, bem de uso comum do povo, essencial à sadia qualidade de vida e sua sustentabilidade. (BRASIL, 1999, p. 1).

Nesse sentido, a escola torna-se um espaço para a construção dessa coletividade e dos valores, assim como, para a compreensão da influência dos comportamentos e suas consequências na biodiversidade e no meio ambiente. Porém, essa responsabilidade deve ter suporte das demais áreas da sociedade, tais como, o Poder Público, órgãos do Sistema Nacional do Meio Ambiente, os meios de comunicação, as empresas, instituições públicas e privadas e a sociedade em geral.

Segundo Minc (2005), há a necessidade da discussão sobre a influência humana no ambiente, na dinâmica ambiental entre os meios biológicos, químicos, físicos e geográficos, na compreensão da interferência que um elemento do ecossistema pode implicar na alteração de todo o seu equilíbrio. Dessa forma, confirma-se que as escolas possuem um papel desafiador e também, fundamental na formação do conhecimento ambiental e consequentemente, na viabilização de ações sustentáveis.

A Educação Ambiental é um dos temas transversais a serem desenvolvidos de forma interdisciplinar, nas diferentes áreas do conhecimento. Como uma globalização de saberes de diferentes Ciências, a Educação Ambiental possibilita ao ambiente escolar o desenvolvimento de distintos conceitos relacionados ao desenvolvimento sustentável e sua aplicabilidade no dia a dia.

Conforme Loureiro (2004),

Educação ambiental é uma perspectiva que se inscreve e se dinamiza na própria educação, formada nas relações estabelecidas entre as múltiplas tendências pedagógicas e do ambientalismo, que têm no "ambiente" e na "natureza" categorias 
centrais e identitárias. Neste posicionamento, a adjetivação "ambiental" se justifica tão somente à medida que serve para destacar dimensões "esquecidas" historicamente pelo fazer educativo, no que se refere ao entendimento da vida e da natureza, e para revelar ou denunciar as dicotomias da modernidade capitalista e do paradigma analítico-linear, não-dialético, que separa: atividade econômica, ou outra, da totalidade social; sociedade e natureza; mente e corpo; matéria e espírito, razão e emoção etc. (LOUREIRO, 2004, p 75).

Desse modo, a Educação ambiental é um meio viabilizador de mudança de comportamento. Podendo ser mediada através da interação dos conhecimentos científicos e teóricos com a experimentação de distintas práticas realizadas no ambiente escolar e externo à escola, desenvolvendo nos discentes, docentes, funcionários, gestores e comunidade, a consciência ecológica e práticas de sustentabilidade (LOUREIRO, 2004). Por outro lado, é notável destacar que:

Ao longo do Ensino Fundamental, a área de Ciências da Natureza tem um compromisso com o desenvolvimento do letramento científico, que envolve a capacidade de compreender e interpretar o mundo (natural, social e tecnológico), mas também de transformá-lo com base nos aportes teóricos e processuais das ciências. Em outras palavras, apreender ciência não é a finalidade última do letramento, mas, sim, o desenvolvimento da capacidade de atuação no e sobre o mundo, importante ao exercício pleno da cidadania. (BRASIL, 2017, p.317).

Para Jacobi (2003), os desafios para os educadores, ao tratar da educação ambiental são, de um lado, o resgate e o desenvolvimento de valores e comportamentos (confiança, respeito mútuo, responsabilidade, compromisso, solidariedade e iniciativa) e de outro, o estímulo a uma visão global e crítica das questões ambientais e a promoção de um enfoque interdisciplinar que resgate e construa saberes. Dessa forma, entende-se a relevância dos conhecimentos a serem construídos, no ensino fundamental, mediante aos conteúdos curriculares estipulados para essa área específica.

\section{A sustentabilidade sob a perceptiva da gestão escolar}

A partir das entrevistas realizadas com as gestoras em três escolas estaduais de ensino fundamental do município de São Sebastião do Caí/RS, organizou-se, nesta seção, um recorte dos resultados dos dados analisados. Para preservar a identidade das gestoras, as interlocutoras foram identificadas pelas letras $\mathrm{A}, \mathrm{B}$ e $\mathrm{C}$.

Quanto à formação acadêmica, as três gestoras são diplomadas em Pedagogia e cursaram Pós graduação. As entrevistadas B e C possuem mais de 5 anos de experiência como gestoras e a interlocutora A, atua há 14 anos nesse cargo.

Compreendendo a formação e o tempo de experiência de cada gestora, foram questionadas sobre as suas concepções sobre a sustentabilidade, sendo esse, um dos objetivos desta pesquisa. As gestoras foram unânimes ao relacionaram sustentabilidade à conservação 
dos recursos naturais e ao planejamento para o futuro das próximas gerações. A gestora A relacionou sustentabilidade com o processo de aprendizagem a ser desenvolvido "por cada indivíduo para se constituir autossustentável”. A gestora B atribuiu o conceito de sustentabilidade à "qualidade de vida". Já a gestora C, não aprofundou o conceito, mas o articulou com o "consumo desenfreado na atualidade".

Essas concepções mostram que o conceito de sustentabilidade construídos por elas, sinalizam os aspectos sociais e os ambientais de forma articulada, visto que as práticas e ações de sustentabilidade não envolvem apenas o meio ambiente, mas as pessoas que nele convivem. Nesse sentido, Gadotti (2008) salienta que ao desenvolvermos o conceito de sustentabilidade não tratamos:

Propriamente da sustentabilidade do planeta, mas, muito mais, da continuação de seus privilégios, em contraste com as necessidades da maioria da população do mundo. Sem uma preocupação social, o conceito de "desenvolvimento sustentável" esvaziase de sentido. Por isso, devemos falar muito mais do "socioambiental" do que do "ambiental", buscando não separar as necessidades do planeta das necessidades humanas. (GADOTTI, 2008, p.49).

Quando o assunto questionado eram as práticas de sustentabilidade que consideravam mais relevantes a serem desenvolvidas com os alunos no espaço escolar e quais as práticas ou ações de sustentabilidade eram desenvolvidas, as respostas tiveram semelhanças e algumas pontuais diferenças.

As gestoras A e C entendem que a falta de recurso humano especializado e a carência de orientação especializada são ausências que implicam no processo de compreensão e construção de práticas de sustentabilidade, uma vez que as informações adquiridas para desenvolverem as ações, são as obtidas na graduação ou por pesquisas em sites. Portanto, acreditam que isso pode ser um entrave para que ocorra a articulação e a contextualização do conhecimento teórico à prática que será promovida junto aos alunos.

As práticas realizadas pelas gestoras das escolas A e B têm em comum a separação do lixo, sendo que a primeira vende o lixo para ter recursos para possíveis investimentos na escola e a segunda doa para um reciclador. Ambas estão planejando colocar em prática um projeto de reaproveitamento da água da chuva pela instalação de calhas e cisternas, porém o recurso financeiro é escasso e o investimento é alto. A escola da gestora B possui projeto para a economia de luz, que vem dando resultados significativos e além disso, o projeto resultou em um prêmio em dinheiro para a escola.

A gestora $\mathrm{C}$ destaca que as ações de sustentabilidade são trabalhadas como conteúdo curricular, porém a prática é pouco perceptível. O que se mantém são lixeiras seletivas no pátio da escola. Segundo Lavezzo (2016), a compreensão dos conceitos ligados à sustentabilidade torna-se a cada dia mais imprescindível, já que a consciência traz à tona as atitudes que devem 
ser reiteradas, modificadas e contextualizadas em sua essência, tanto em novos comportamentos como em hábitos.

Dessa forma, os desafios e as possibilidades relatados pelas gestoras confirmam o quanto a formação continuada dos profissionais, a metodologia de ensino e a participação da comunidade escolar influenciam para a concretização das ações de sustentabilidade que são mediadas pela gestão, pois a "educação para o desenvolvimento sustentável está a emergir como um conceito dinâmico que engloba uma nova perspectiva de educação que procura integrar todas as pessoas de modo a levar a assumir a responsabilidade de criar um futuro sustentável”. (FREIRE, 2007, p. 147).

\section{Considerações Finais}

A presente pesquisa teve o objetivo de analisar a concepção de sustentabilidade construída pelos gestores escolares e compreender como possibilitam/mediam ações de sustentabilidade nas escolas.

A partir da análise dos dados, houve a possibilidade de compreender que tanto a institucionalização da gestão democrática, como o conceito e as práticas de sustentabilidade, são processos que ainda estão em construção.

Além desse aspecto, percebeu-se que para o desenvolvimento da Educação ambiental - mesmo sendo prevista e regulamentada por lei, evidenciada nos Parâmetros Curriculares Nacionais - PCNs e na Base Nacional Comum Curricular - BNCC - a escassez de formação continuada, a redução dos recursos humanos, o contingenciamento de investimentos na área e a desvalorização do profissional da educação, repercutem em entraves e desafios para a construção de ações sustentáveis no ambiente escolar.

No entanto, vários pontos positivos puderam ser elencados. Dentre eles, as práticas bem sucedidas dos projetos desenvolvidos nas escolas, os quais estão voltados à construção de práticas sustentáveis. Nesse contexto, a mediação da gestão escolar pôde ser entendida como potencializadora da construção da consciência ecológica e da promoção de ações sustentáveis. Contudo, avanços em pesquisas, nessa área de estudo, mostram-se necessários.

\section{Referências}

BRASIL. Política Nacional de Educação Ambiental. Brasília. DF: Planalto. 1999. Disponível em: <http://www.planalto.gov.br/ccivil_03/LEIS/L9795.htm>. Acesso em 15 de jul. 2018.

FREIRE, Ana Maria. Educação para a Sustentabilidade: Implicações para o Currículo Escolar e para a Formação de Professores. Disponível em: 
http://www.pos.ajes.edu.br/arquivos/referencial_20120913100933.pdf. Acesso em: 07 jun. 2016.

GADOTTI, Moacir. Ecopedagogia e educação para a sustentabilidade. Disponível em: <http://www.educacao.pr.gov.br/arquivos/File/det/palestra3_eco_educacao_sustentabilidade gadotti_1998.pdf> . Acesso em: 05 jun. 2016.

GADOTTI, Moacir. Educar para a Sustentabilidade. Disponível em: <http://basessibi.c3sl.ufpr.br/brapci/_repositorio/2009/11/pdf_49dbfdec4a_0006661.pdf> . Acesso em: 11 julho 2017.

GADOTTI, Moacir. Pedagogia da Terra. Disponível em: 〈https://books.google.com.br>. Acesso em: 05 jun. 2017.

JACOBI, Pedro. Educação Ambiental, cidadania e sustentabilidade. Cadernos de pesquisa. $\mathrm{N}^{\circ} 118$, p. 189-205, mar.2003. Disponível em:

<file:///C:/Users/Usuario/Desktop/TCC/educa\%C3\%A7\%C3\%A30\%20ambiental,\%20cidada nia\%20e\%20sustentabilidade..pdf $>$. Acesso em: 10 jun.2016.

LAVEZZO, César Augusto Lotti. Sustentabilidade. Revista Eletrônica: Gestão em foco. Unifia. Amparo. p 4- 21. 2016.

Disponívelem: $<$ http://unifia.edu.br/revista_eletronica/revistas/gestao_foco/artigos/ano2016/01 3_sustentabilidade.pdf $>$. Acesso em: 23 de abril 2018.

LIBÂNEO, José Carlos. Organização e gestão da escola. Teoria e prática. São Paulo. $6^{\circ}$ edição. Editora Heccus. 2004.

LIBÂNEO, José Carlos; OLIVEIRA, João Ferreira; TOSCHI, Mirza Seabra. Educação Escolar: Políticas, Estrutura e Organização. São Paulo. 10º edição. Editora Cortez. 2012.

LOUREIRO, C.F.B. O que significa transformar em Educação Ambiental. Zakrzevski, S.B.; Barcelos, V. (Orgs.) Educação ambiental e compromisso social. Erechim: EdiFapes. 2004.

MINC, Carlos. Ecologia e cidadania. São Paulo. Editora Moderna. 2005.

MINISTÉRIO DA EDUCAÇÃO. Base Nacional Comum Curricular. Brasília, DF: MEC, 2015. Disponível em: <http://basenacionalcomum.mec.gov.br/abase/>. Acesso em: 21 jun. 2018.

OLIVEIRA, João Ferreira de; MORAES, Karine Nunes de; DOURADO, Luis

Fernando. Gestão escolar democrática: definições, princípios e mecanismos de implantação. Brasília, 2012. Disponível em: <http://escoladegestores.mec.gov.br/site/4sala_politica_gestao_escolar/pdf/texto2_1.pdf>. Acesso em: 14 de dez. 2015.

RIOS, Terezinha Azeredo. Competência ou competências - o novo e o original na formação de professores. Rio de Janeiro: DP\&A, 2002. 